\title{
A Potential Role for Fructosamine-3-Kinase in Cataract Treatment
}

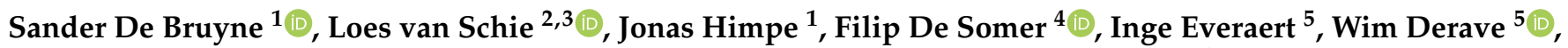 \\ Caroline Van den Broecke ${ }^{6}$, Manon Huizing ${ }^{7}$, Nezahat Bostan ${ }^{7}$, Marijn Speeckaert ${ }^{8}{ }^{\mathbb{D}}$, Nico Callewaert ${ }^{2,3}$, \\ Elisabeth Van Aken ${ }^{9, *(1)}$ and Joris R. Delanghe $1, *(\mathbb{D}$
}

check for updates

Citation: De Bruyne, S.; van Schie, L.; Himpe, J.; De Somer, F.; Everaert, I.; Derave, W.; Van den Broecke, C.; Huizing, M.; Bostan, N.; Speeckaert, M.; et al. A Potential Role for Fructosamine-3-Kinase in Cataract Treatment. Int. J. Mol. Sci. 2021, 22, 3841. https://doi.org/10.3390/ ijms22083841

Academic Editors: Cheorl-Ho Kim and Julien Dairou

Received: 29 December 2020

Accepted: 2 April 2021

Published: 7 April 2021

Publisher's Note: MDPI stays neutra with regard to jurisdictional claims in published maps and institutional affiliations.

Copyright: (c) 2021 by the authors. Licensee MDPI, Basel, Switzerland. This article is an open access article distributed under the terms and conditions of the Creative Commons Attribution (CC BY) license (https:/ / creativecommons.org/licenses/by/ $4.0 /)$.
1 Department of Diagnostic Sciences, Ghent University, 9000 Ghent, Belgium; sanderR.debruyne@ugent.be (S.D.B.); jonas.himpe@ugent.be (J.H.)

2 VIB-UGent Center for Medical Biotechnology, VIB, 9052 Ghent, Belgium; loes.vanschie@vib-ugent.be (L.v.S.); nico.callewaert@vib-ugent.be (N.C.)

3 Department of Biochemistry and Microbiology, Ghent University, 9052 Ghent, Belgium

4 Department of Human Structure and Repair, 9000 Ghent, Belgium; Filip.DeSomer@ugent.be

5 Department of Movement and Sport Sciences, Ghent University, 9000 Ghent, Belgium; Inge.Everaert@UGent.be (I.E.); wim.derave@ugent.be (W.D.)

6 Department of Pathology, Ghent University Hospital, 9000 Ghent, Belgium; caroline.vandenbroecke@azstlucas.be

7 Antwerp Biobank, Antwerp University Hospital, 2650 Antwerp, Belgium; manon.huizing@uza.be (M.H.); nezahat.bostan@uza.be (N.B.)

8 Department of Internal Medicine and Pediatrics, Ghent University, 9000 Ghent, Belgium; marijn.speeckaert@ugent.be

9 Department of Head and Skin, Ghent University, 9000 Ghent, Belgium

* Correspondence: elisabeth.vanaken@ugent.be (E.V.A.); joris.delanghe@ugent.be (J.R.D.)

Abstract: Cataracts are the major cause of blindness worldwide, largely resulting from aging and diabetes mellitus. Advanced glycation end products (AGEs) have been identified as major contributors in cataract formation because they alter lens protein structure and stability and induce covalent crosslinking, aggregation, and insolubilization of lens crystallins. We investigated the potential of the deglycating enzyme fructosamine-3-kinase (FN3K) in the disruption of AGEs in cataractous lenses. Macroscopic changes of equine lenses were evaluated after ex vivo intravitreal FN3K injection. The mechanical properties of an equine lens pair were evaluated after treatment with saline and FN3K. AGE-type autofluorescence (AF) was measured to assess the time-dependent effects of FN3K on glycolaldehyde-induced AGE-modified porcine lens fragments and to evaluate its actions on intact lenses after in vivo intravitreal FN3K injection of murine eyes. A potential immune response after injection was evaluated by analysis of IL-2, TNF $\alpha$, and IFN $\gamma$ using an ELISA kit. Dose- and timedependent AF kinetics were analyzed on pooled human lens fragments. Furthermore, AF measurements and a time-lapse of macroscopic changes were performed on intact cataractous human eye lenses after incubation with an FN3K solution. At last, AF measurements were performed on cataractous human eyes after crossover topical treatment with either saline- or FN3K-containing drops. While the lenses of the equine FN3K-treated eyes appeared to be clear, the saline-treated lenses had a yellowish-brown color. Following FN3K treatment, color restoration could be observed within $30 \mathrm{~min}$. The extension rate of the equine FN3K-treated lens was more than twice the extension rate of the saline-treated lens. FN3K treatment induced significant time-dependent decreases in AGE-related AF values in the AGE-modified porcine lens fragments. Furthermore, in vivo intravitreal FN3K injection of murine eyes significantly reduced AF values of the lenses. Treatment did not provoke a systemic immune response in mice. AF kinetics of FN3K-treated cataractous human lens suspensions revealed dose- and time-dependent decreases. Incubation of cataractous human eye lenses with FN3K resulted in a macroscopic lighter color of the cortex and a decrease in AF values. At last, crossover topical treatment of intact human eyes revealed a decrease in AF values during FN3K treatment, while showing no notable changes with saline. Our study suggests, for the first time, a potential additional role of FN3K as an alternative treatment for AGE-related cataracts. 
Keywords: advanced glycation end products; cataract; deglycation; fructosamine-3-kinase; therapeutics

\section{Introduction}

Cataracts are a global public health problem with a rising prevalence in both industrialized and third-world countries [1]. It is the major cause of blindness worldwide, affecting about 65.2 million people [2] and one of the principally targeted avoidable eye conditions in the VISION 2020 project for the World Health Organization [3]. While there is a wide range of potential causes, aging is considered as the most important risk factor with excessive exposure to ultraviolet light and related free radical damage of crystallins being principal pathogenic components [4]. Moreover, due to a very low protein turnover, crystallins belong to the longest-lived human proteins and are prone to progressive glycation with age. $\alpha-, \beta$ - and $\gamma$-crystallins make up $>90 \%$ of the total dry mass of the lens [5]. In the process of protein glycation, reducing sugars and carbonyls react with free amino groups, forming adducts that can then rearrange and react further, eventually leading to protein cross-links. This process in which advanced glycation end products (AGEs) are formed is generally known as the Maillard reaction, a very complex and quite incompletely understood non-enzymatic set of reactions [4]. An overview of the steps involved in the endogenous formation of AGEs can be found in Figure 1.

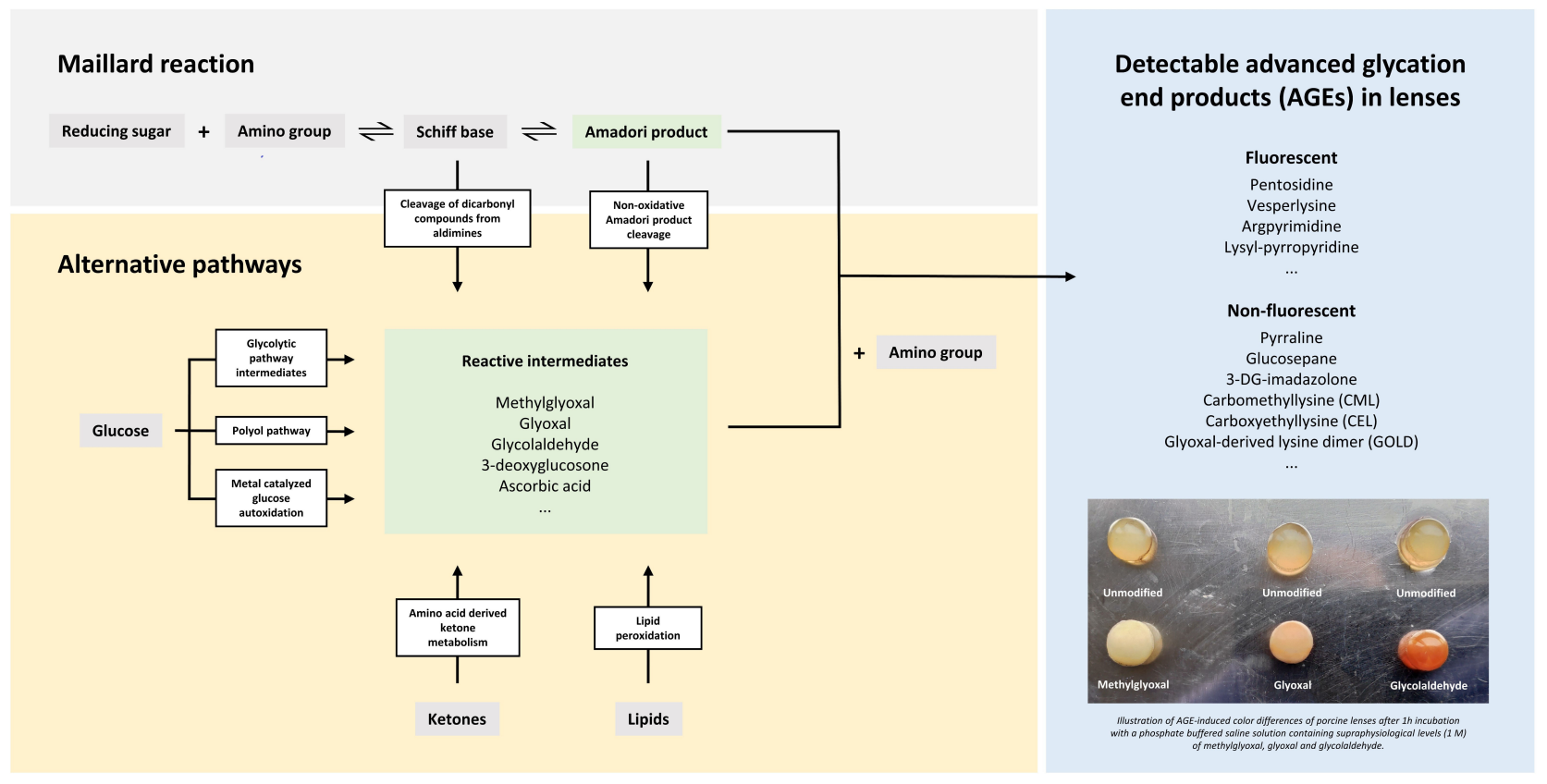

Figure 1. Advanced glycation end products (AGEs) are synthesized endogenously via the Maillard reaction and several alternative pathways [6]. In the early steps of the Maillard reaction, an iminine intermediate (Schiff base) is formed by the reaction of a reducing sugar (e.g., glucose) with a protein-bound amine or free amino acid. The labile Schiff base can produce highly reactive dicarbonyls (e.g., methylglyoxal) or rearrange into stable Amadori products. In the advanced steps of the Maillard reaction, the Amadori products undergo complex rearrangements, cleavage and covalent binding reactions, which eventually give rise to the generation of AGEs, which are stable adducts and cross-links of proteins [6,7]. Highly reactive carbonyls can also be generated from glycolytic pathway intermediates, the polyol pathway, glucose autoxidation, ketones generated by the breakdown of amino acids and lipid peroxidation. Those carbonyl compounds initiate the process of advanced glycation directly, eventually leading to the synthesis of a wide range of fluorescent (e.g., pentosidine) and non-fluorescent AGEs (e.g., glucosepane), which can be found in human tissues including eye lenses [6]. 
The Maillard theory with progressive accumulation of AGEs may contribute not only to general aging, but also to the pathology of metabolic diseases, such as diabetes and atherosclerosis, and neurodegenerative diseases [8-10]. In the lens, AGEs have been characterized during normal aging as well as in a diabetic context [9]. Non-enzymatic glycation of lens proteins is a major factor responsible for cataract formation by altering lens protein structure and stability and by inducing covalent cross-linking, aggregation and insolubilization of lens crystallins [11]. Accumulation of AGEs is more substantial in diabetics as the elevated glucose concentration accelerates the production of AGEs [12]. In aging and diabetes, increased concentrations of dicarbonyl compounds (e.g., methylglyoxal and glyoxal) also result in AGE cross-links on $\alpha$-crystallins with a consequent reduction of chaperone activity, enhanced $\alpha \beta$-crystallin content, and the formation of dense aggregates [4]. Concomitantly, prevalence of cataracts in diabetics is five-fold higher than among non-diabetics [12]. AGEs also contribute to cataracts through their cytotoxic effect on epithelial lens cells through the induction of apoptosis in a NF-kappa b-dependent manner. Furthermore, AGEs accumulate in aging human lens capsules, suggesting a role in the transforming growth factor beta-2-mediated fibrosis of epithelial lens cells during posterior capsule opacification [13].

As current surgical cataract treatment by phacoemulsification is relatively expensive and the number of practicing ophthalmologists is small in developing countries, there is a growing demand for affordable cataract treatment options accessible to a large number of patients. AGE-inhibiting or disrupting compounds may have efficacy in the prevention and treatment of AGE-related cataract formation. Present knowledge suggests that FN3K is a part of the natural cellular repair mechanisms that control non-enzymatic glycation of proteins and is more active in tissues with a long half-life (e.g., brain, erythrocyte, eye lens) [14-16]. The FN3K enzyme is known to phosphorylate both free and protein-bound fructosamines (Amadori rearrangement products) on the third carbon of their sugar moiety making them unstable, which leads to their detachment from proteins with concomitant regeneration of the unglycated amine [17]. This process eventually prevents the formation of AGEs. Lower AGE levels have been reported in populations with higher concentration and activity levels of FN3K [18], and a protective role of the enzyme has recently been documented against the onset of vascular complications in the diabetic population [19]. Moreover, FN3K has successfully been used in the deglycation of several tissue types such as heart valves [20], nails [21,22] and kidney sections [23].

Next to the classical view of FN3K being an intracellular enzyme that has primary (low molecular mass) glycation products as a unique substrate, recent research suggested an additional potential role of FN3K in the direct disruption of retinal AGEs [24]. However, it is still unexplored whether FN3K treatment would also result in the disruption of AGEs and cross-linked structures of cataractous lenses. Therefore, we studied the effects of FN3K treatment on cataractous lenses of both animal and human origin, mainly by assessing the effects of FN3K treatment on the amount of Maillard-type autofluorescence.

\section{Results}

2.1. In Vitro Kinase Activity of FN3K, but Not FN3K-K41L, Is Dose-Dependent

The kinase activity of FN3K was dose-dependent, with $108 \mathrm{pmol} \mu \mathrm{g}^{-1} \mathrm{~min}^{-1}$ phosphate released (derived from regression in the linear range), whereas FN3K-K41L resulted in minimal phosphate release $\left(0.2 \mathrm{pmol} \mathrm{\mu g} \mathrm{g}^{-1} \mathrm{~min}^{-1}\right.$, Figure 2). However, we do not know whether this lack of activity is purely due to the K41L mutation in the catalytic center, or to misconformation or aggregation. This limitation should be taken into account when using FN3K-K41L as a negative control sample for FN3K in in vivo functional experiments.

\subsection{Ex Vivo Intravitreal FN3K Treatment of Equine Lenses}

While the lenses of the equine FN3K-treated eyes $(n=3)$ appeared to be clear, the saline-treated lenses $(n=3)$ had a yellowish-brown color. Following FN3K treatment, complete color restoration could be observed within $30 \mathrm{~min}$ (Figure 3A). For a force up to 
$5 \mathrm{~N}$, the extension rate of one of the equine FN3K-treated lenses appeared to be more than twice the extension rate of the saline-treated lens (Figure 3B).

\section{Kinase activity}

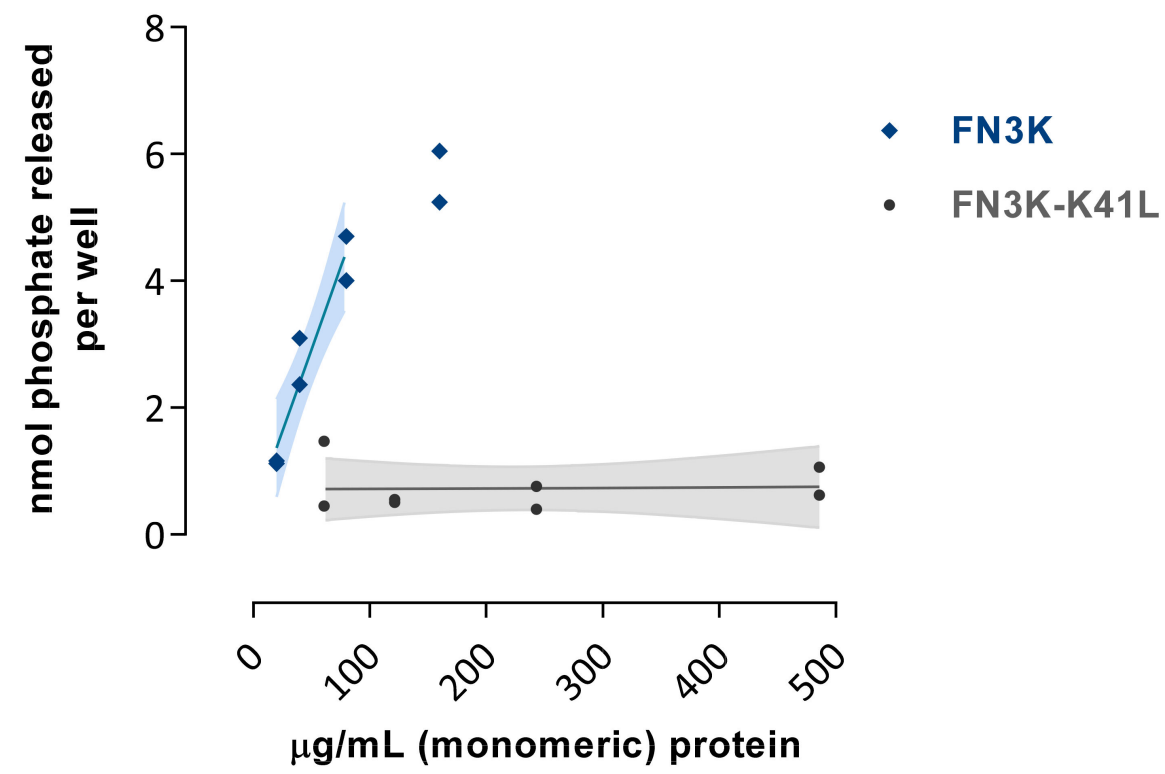

Figure 2. Kinase activity of FN3K and the inactive mutant enzyme FN3K-K41L as assessed by the amount of phosphate released per well (nmol) using a 1-deoxy-1-morpholino-D-fructose (DMF) acceptor substrate at increasing enzymatic concentration levels $(\mu \mathrm{g} / \mathrm{mL})$. Data are depicted as single data points with their fitted regression line in the linear range and 95\% confidence interval.

A

Equine

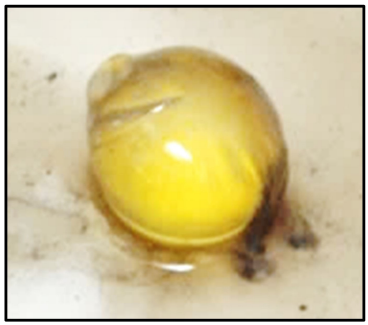

I. Saline

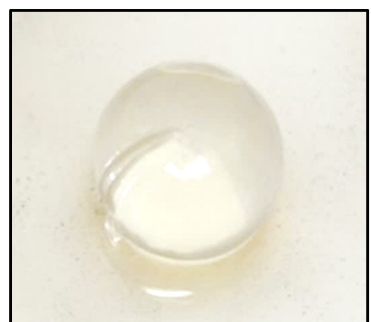

II. FN3K

B

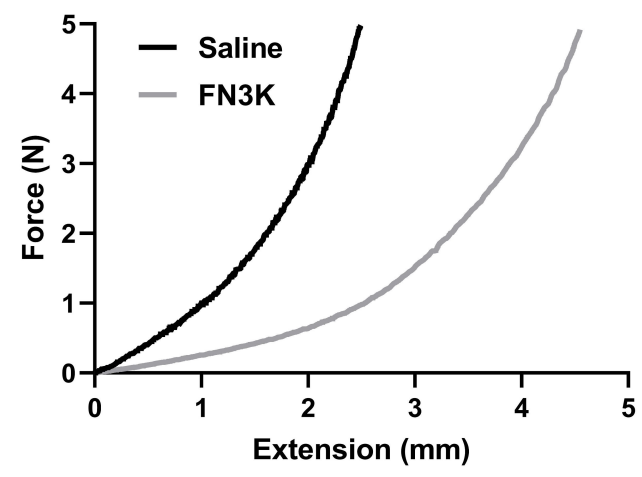

Figure 3. (A) Macroscopic aspect of a representative ex vivo saline-(I) and fructosamine-3-kinase (FN3K) treated (II) lens originating from equine eye pairs. (B) Extension rate of lenses originating from an equine eye pair treated with either saline or FN3K. N, newton. 


\subsection{FN3K Treatment of AGE-Modified Porcine Lens Fragments Reduces Maillard-Type Autofluorescence}

Figure $4 \mathrm{~A}$ shows the autofluorescence (AF) values of the porcine lens fragments $(n=11)$ at baseline, after AGE-modification and after FN3K treatment ( $1 \mathrm{~h}, 2 \mathrm{~h}$ and $3 \mathrm{~h}$ incubation). Repeated measures ANOVA revealed significant changes between the different treatment groups $(p<0.0001)$. AGE-related AF values significantly increased in all the porcine lens fragments after incubation with $25-\mathrm{mM}$ glycolaldehyde (AF value $0.022 \pm 0.011$ ) compared to baseline levels (AF value $0.0031 \pm 0.00072, p=0.0002$ ). Subsequently, FN3K treatment induced significant and ongoing decreases of AF values after $1 \mathrm{~h}$ (AF value $0.017 \pm 0.0077$, $-22.7 \%, p=0.0021$ ), $2 \mathrm{~h}$ (AF value $0.013 \pm 0.0069,-40.9 \%, p=0.0002$ ) and $3 \mathrm{~h}$ (AF value $0.0086 \pm 0.0046,-60.9 \%, p=0.0002$ ) compared to the levels obtained after glycolaldehyde modification. No notable changes were observed after control treatment (cofactors ATP and $\mathrm{MgCl}_{2}$ solely) of the AGE-modified lens fragments ( $n=4$, Figure $4 \mathrm{~B}$ ).
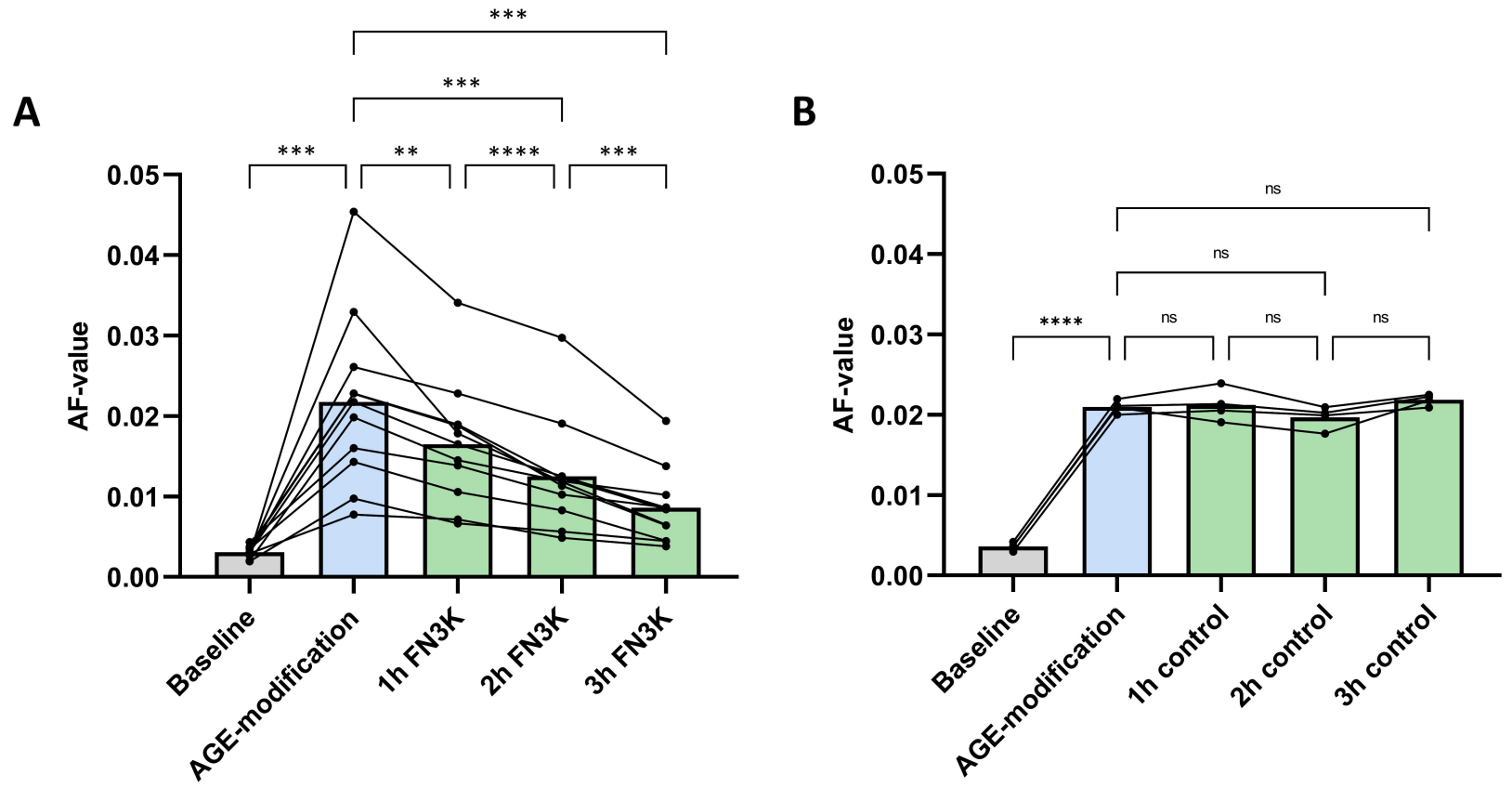

Figure 4. (A) Autofluorescence (AF) values of glycolaldehyde-induced advanced glycation end product (AGE)-modified porcine lens fragments after fructosamine-3-kinase (FN3K, $n=11)$ and $(\mathbf{B})$ control $(n=4)$ treatment with the cofactors ATP and $\mathrm{MgCl}_{2}$ solely. The bars represent the mean. ${ }^{* * *} p<0.0001 ;{ }^{* * *} p<0.001 ;{ }^{* *} p<0.01 ;$ ns, non-significant.

\subsection{In Vivo Intravitreal FN3K Injection of Murine Eyes Reduces Maillard-Type Autofluorescence}

Concerning the AF values, the Wilcoxon test revealed that the median of the differences between saline- $(n=20$, median 0.033 , IQR $0.021-0.051)$ and FN3K- $(n=20$, median 0.024 , IQR 0.019-0.029) treated lenses was statistically different $(p=0.0042$, Figure 5A). Figure 5B illustrates the median fluorescence emission spectra ( $400-620 \mathrm{~nm}$ range) for both treatment conditions. 
A

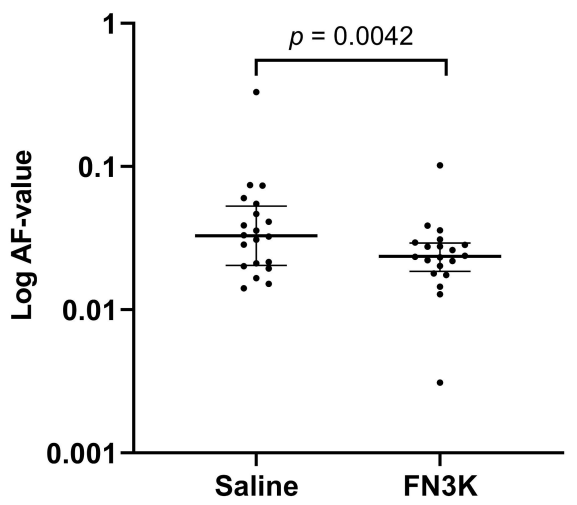

B

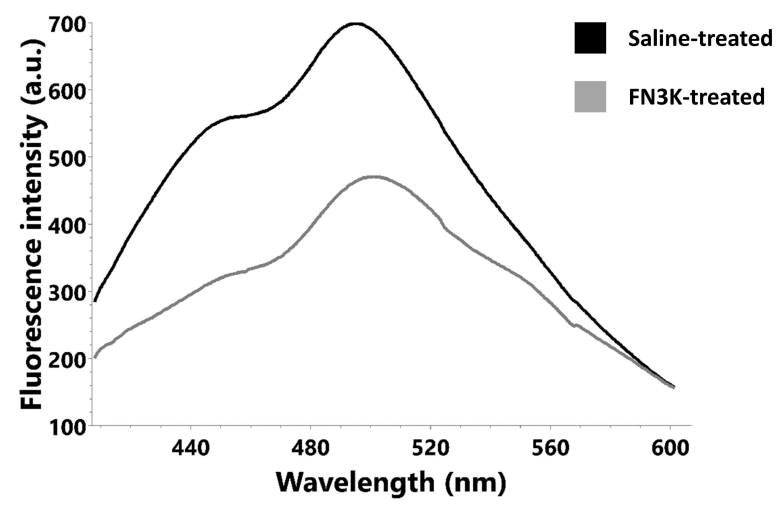

Figure 5. (A) Autofluorescence (AF) values of the enucleated lenses of $o b / o b(n=20)$ mice after in vivo intravitreal injection with saline (left eye) or FN3K (right eye). Data are displayed as the median and interquartile range (log scale). (B) Median fluorescence emission spectra (400-620 nm range) of the murine lenses after in vivo saline (black line) or FN3K (grey line) treatment. A.u., arbitrary units; nm, nanometer.

Figure 6A displays the hematoxylin and eosin (HE) stained tissue section of a salinetreated lens and its FN3K-treated counterpart. In both lenses, the lens capsule was present. In the cortex of the saline-treated eye, the parallel arrangement of the lens fibers was disturbed with a disorganized aspect of the subcapsular layer. While the cortex of the FN3K-treated eye was also characterized by disorganized zones of lens fibers, multiple subcortical zones showed the presence of organized lens fibers. Furthermore, lenses of the FN3K-treated mice eyes appeared to be more spherical in shape compared to the more flattened lenses of saline-treated eyes. Figure 6B shows a close-up on the cortical lens fibers. In the FN3K-treated lens, fibers are tightly packed with little intercellular space and are concentrically arranged. In contrast, the architecture of the cortical lens fibers in the control-treated counterpart is disturbed with the presence of vacuoles and loss of parallel organization.

A

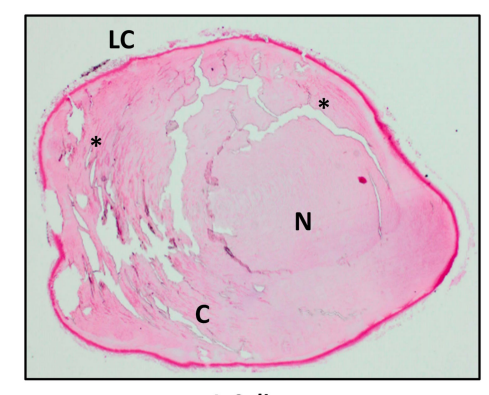

I. Saline

B

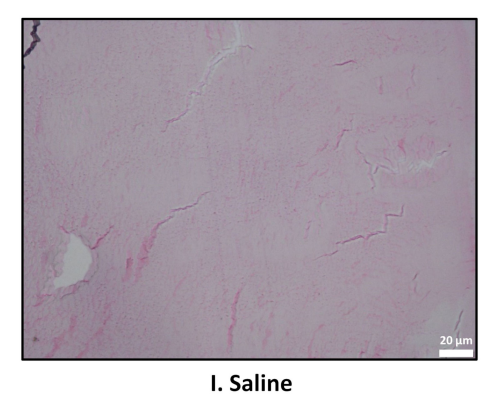

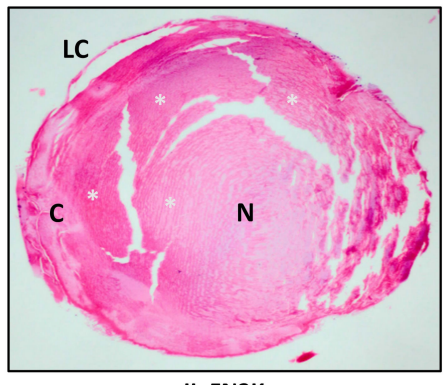

II. FN3K

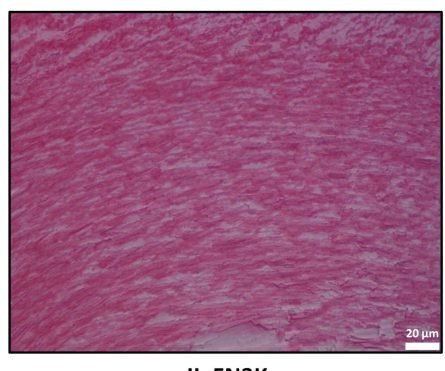

II. FN3K

Figure 6. (A) Hematoxylin and eosin-stained sections of a saline (I) and FN3K treated (II) lens originating from the same $o b / o b$ mouse. Disorganized and organized zones of lens fibers are indicated with black and white asterisks, respectively. C, cortex; LC, lens capsule; N, nucleus. (B) Close-up on the cortical lens fibers of the saline (I) and FN3K treated (II) lens. 


\subsection{FN3K Treatment Does Not Provoke a Systemic Immune Response in Mice}

In all non-treated mice $(n=5)$ serum levels of IL-2, TNF $\alpha$ and IFN $\gamma$ were below detection limits $(2 \mathrm{pg} / \mathrm{mL}, 8 \mathrm{pg} / \mathrm{mL}$ and $16 \mathrm{pg} / \mathrm{mL}$, respectively). In a large majority of FN3K-treated mice ( 45 out of 55), levels of these 3 cytokines were below detection limits as well. In several serum samples (10 out of 55), one of the three cytokines tested for was upregulated. However, cytokine levels were not consistently high within treatment groups and in general were very low (below $120 \mathrm{pg} / \mathrm{mL}$ ). From this, we could conclude that intravitreal injection of a therapeutic FN3K mixture did not consistently provoke a systemic immune response. ELISA results are enclosed in Appendix A.

\subsection{Gel Filtration of Human Cataractous Lens Fractions Reveals Breakdown Products after FN3K Treatment}

Comparison of gel filtration patterns of urea-soluble pooled human lens fractions before and after FN3K treatment (Figure 7) showed a reduction of the mean molecular mass of the fructose containing compounds. In the untreated lens, a peak corresponding to a molecular mass of $\pm 2500 \mathrm{Da}$ and a second minor peak corresponding to $1660 \mathrm{Da}$ were observed, which indicates the presence of high-molecular mass structures such as cross-linked AGEs. In the FN3K treated lens fractions, a series of breakdown products with a molecular mass ranging between 1500 and 2500 Da were detected. This strengthens our hypothesis that the enzyme is not only active against low-molecular mass glycation products, but also possesses activity against high-molecular mass compounds (AGEs).

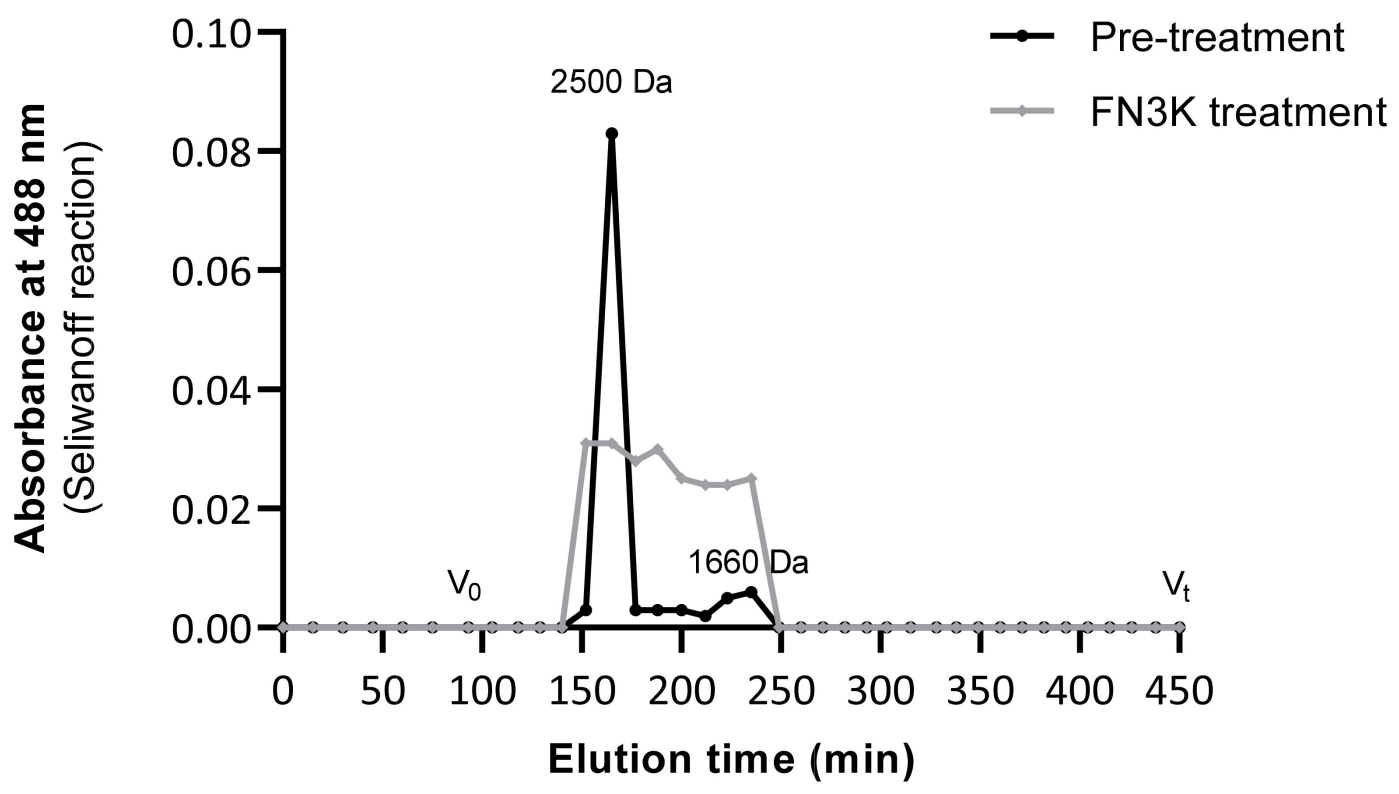

Figure 7. Gel filtration patterns (Sephadex ${ }^{\circledR}$ G-25 Fine resin) of urea-soluble lens fractions before and after FN3K treatment showing the absorbance at $488 \mathrm{~nm}$ (Seliwanoff reaction) of high-molecular mass fructose containing compounds (AGEs) as a function of the elution time. $\mathrm{V}_{0}(>5 \mathrm{kDa})$ indicates the void volume, $\mathrm{Vt}(<500 \mathrm{Da})$ the terminal volume.

\subsection{Autofluorescence Kinetics of FN3K Treatment on Cataractous Human Lens Suspensions}

Figure $8 \mathrm{~A}$ shows the mean change (\%) of AF values compared to baseline levels for cataractous human lens suspensions in function of incubation time at a higher concentration range of both the active and mutant FN3K enzyme: $125 \mu \mathrm{g} / \mathrm{mL}, 62.5 \mu \mathrm{g} / \mathrm{mL}$ and $31.8 \mu \mathrm{g} / \mathrm{mL}$. While only small or negligible changes of AF values were noticed in the case of the mutant enzyme, remarkable decreases were observed for the active enzyme. Similar kinetics were found at all concentrations levels. The most pronounced decrease of AF values was observed after $1 \mathrm{~h}$ incubation (43.6-49.7\% decrease compared to baseline). While after the second hour some additional progression of the chemical reaction was 
observed (56.7-70.8\% decrease compared to baseline), AF values remained rather stable after the third hour (56.6-77.4\% decrease compared to baseline). The latter suggests the completion of the reaction process at the end of the experiment. Figure $8 \mathrm{~B}$ shows the mean change (\%) of $\mathrm{AF}$ values compared to baseline levels in function of incubation time at a lower concentration range of active FN3K $(12.5 \mu \mathrm{g} / \mathrm{mL}, 6.25 \mu \mathrm{g} / \mathrm{mL}$ and $1.25 \mu \mathrm{g} / \mathrm{mL})$. In contrast to the experiment performed in the higher range, a more notable time- and dosedependent effect was observed. While similar kinetics were noted for lens suspensions incubated with $12.5 \mu \mathrm{g} / \mathrm{mL}$ and $6.25 \mu \mathrm{g} / \mathrm{mL}$ of active FN3K, the reaction process appeared to be explicitly slower for suspensions incubated with $1.25 \mu \mathrm{g} / \mathrm{mL}$. At all concentration levels, an additional decrease of AF values was seen after $3 \mathrm{~h}$ of incubation which suggests an ongoing reaction process. Additional control experiments revealed that neither the added ATP nor the ADP released by the active enzyme, was responsible for the observed decreases in AF after FN3K treatment (Appendix B).

A

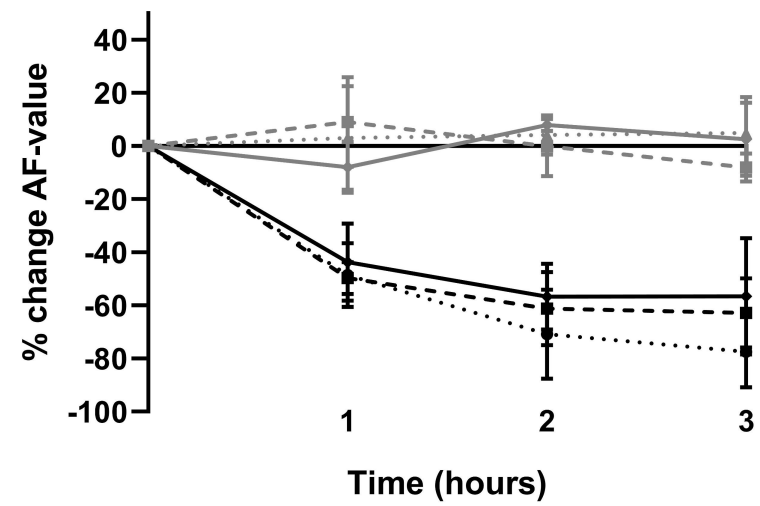

B

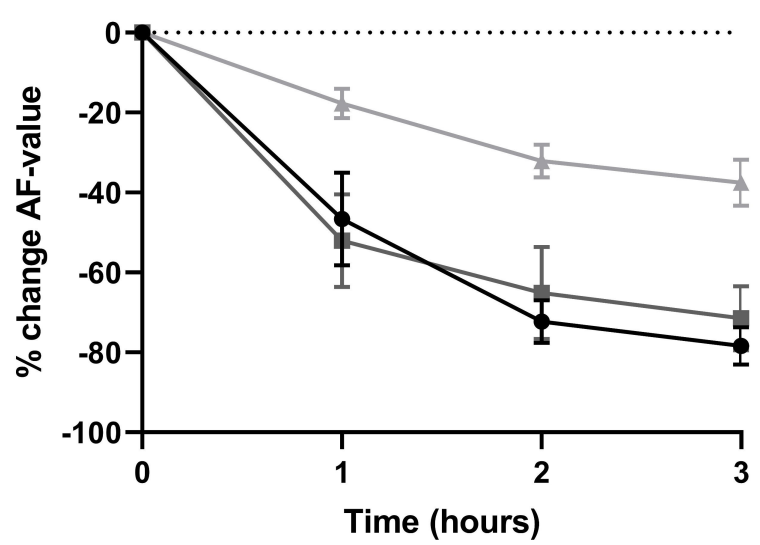

$\rightarrow 125 \mu \mathrm{g} / \mathrm{mL}$ mutant FN3K

- $62.5 \mu \mathrm{g} / \mathrm{mL}$ mutant FN3K

... $31.8 \mu \mathrm{g} / \mathrm{mL}$ mutant FN3K

$\rightarrow 125 \mu \mathrm{g} / \mathrm{mL}$ active FN3K

-.. $62.5 \mu \mathrm{g} / \mathrm{mL}$ active FN3K

•. $31.8 \mu \mathrm{g} / \mathrm{mL}$ active FN3K $\rightarrow 12.5 \mu \mathrm{g} / \mathrm{mL}$ active FN3K
$-6.25 \mu \mathrm{g} / \mathrm{mL}$ active FN3K
$-1.25 \mu \mathrm{g} / \mathrm{mL}$ active FN3K

Figure 8. (A) Dose- and time-dependent changes (\%) in autofluorescence (AF) values after treatment of a cataractous human lens suspension with active and mutant fructosamine-3-kinase (FN3K) in a higher concentration range: $125 \mu \mathrm{g} / \mathrm{mL}$, $62.5 \mu \mathrm{g} / \mathrm{mL}$ and $31.8 \mu \mathrm{g} / \mathrm{mL}$. (B) Dose- and time-dependent changes (\%) in AF values after treatment with active FN3K in a lower concentration range $(12.5 \mu \mathrm{g} / \mathrm{mL}, 6.25 \mu \mathrm{g} / \mathrm{mL}$ and $1.25 \mu \mathrm{g} / \mathrm{mL})$. Data are presented as the mean of in triplo performed experiments with the standard error of the mean.

\subsection{Incubation of Cataractous Human Eye Lenses with FN3K}

Figure 9A shows a time-lapse of the macroscopic changes observed after FN3K treatment of a cataractous human eye lens. After $30 \mathrm{~min}$, an improvement of the color of the cortex and homogeneity could be observed. During a follow-up in the subsequent $2.5 \mathrm{~h}$, the light exposure was changed, which hampered the interpretation of the color intensities in the pictures. However, independent of light exposure differences, a further amelioration of the color of the cortex and homogeneity could be observed. Some minor additional improvements were found at the end of the monitoring period (after $3 \mathrm{~h}$ ). No remarkable color changes could be observed in the case of the saline-treated lens (Figure 9B). For 
another cataractous human eye lens, a Mann-Whitney U test on spectral measurements of the whole lens revealed a statistically significant decrease of the AF value after ex vivo incubation of the intact eye lens with FN3K (median 0.037, IQR 0.018-0.063) compared to baseline levels (median 0.069, IQR $0.033-0.20, p=0.0011$ ). AF values appeared to be significantly lower at the ventral surface of the lens (median 0.036, IQR 0.029-0.13) compared to the dorsal surface (median 0.14, IQR 0.057-0.34, $p=0.019$ ). Furthermore, AF values at the dorsal surface of the lens showed a stronger decrease after FN3K treatment (median 0.048, IQR $0.022-0.11, p=0.0084$ ) compared to the ventral surface (median 0.024, IQR 0.017-0.047, $p=0.029$, Figure 9 C).

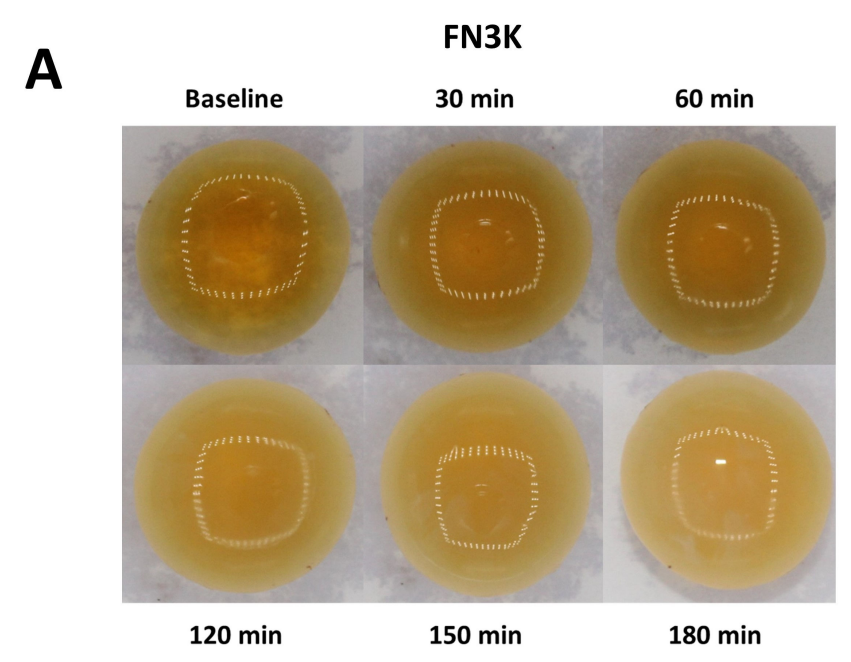

B

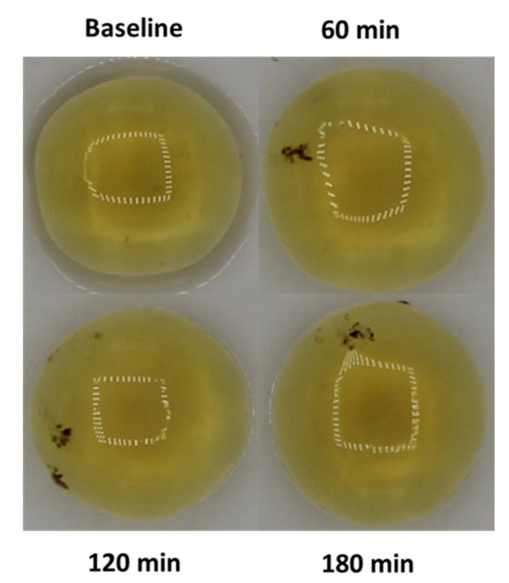

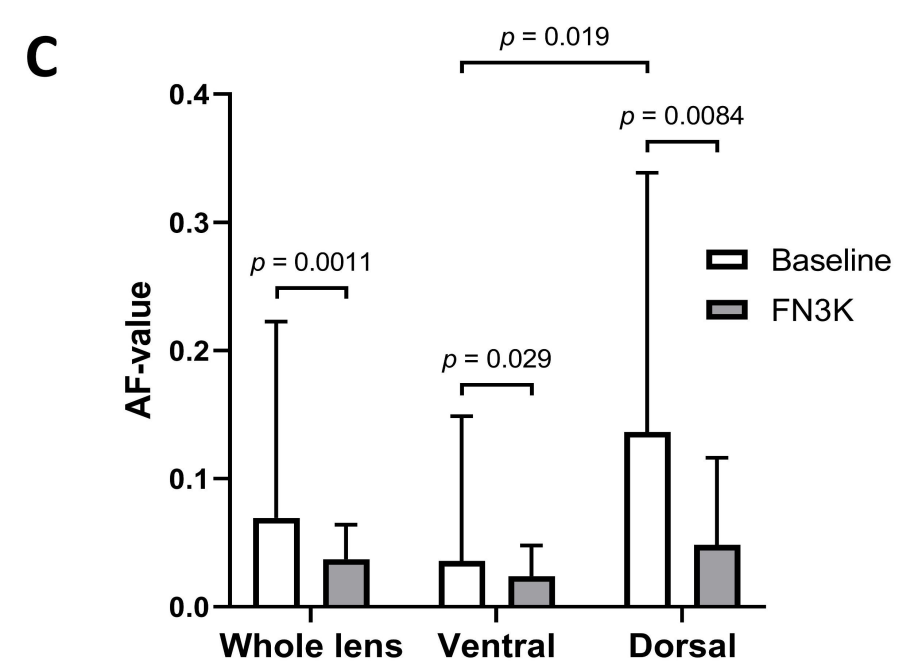

Figure 9. Time-lapse of the macroscopic changes observed after (A) ex vivo fructosamine-3-kinase (FN3K) treatment and (B) saline treatment of cataractous human eye lenses originating from two different patients. After 30 min, an improvement of the color of the cortex and homogeneity could be observed. During a follow-up in the subsequent $2.5 \mathrm{~h}$, the light exposure was changed, which hampered the interpretation of color intensities in the pictures. However, independent of light exposure differences, a further amelioration of the color of the cortex and homogeneity could be observed. No remarkable macroscopic changes could be observed in the case of the saline-treated lens. (C) Autofluorescence (AF) values displayed as the median and interquartile range of a cataractous human eye lens at 30 different measurement locations at baseline and after FN3K treatment for the ventral, dorsal, and whole lens surface.

\subsection{Topical Treatment of Post-Mortem Human Eyes}

For the left eye of a 78-year-old cataract patient, treatment with saline-containing drops did not reveal noteworthy changes to the AF value. However, after crossover treatment 
with FN3K, a decrease of 53.9\% was observed. For the right eye, a rather small decrease of $16.4 \%$ was noted after FN3K treatment, while treatment with saline did not reveal notable changes. The smaller decrease in the right eye can potentially be attributed to the fact that the baseline AF value of the patient's left eye (AF value $=0.0166$ ) appeared to be higher than that of the right eye (AF value $=0.0101)$, indicating a higher content of fluorescent AGEs and therefore a higher level of potential substrates. The results are summarized in Table 1.

Table 1. Maillard-type autofluorescence values (AF values) after crossover topical treatment with a saline and FN3K solution of post-mortem eyes from a 78-year old cataract patient.

\begin{tabular}{|c|c|c|c|c|}
\hline Type of Topical Treatment & Time Interval & $\begin{array}{c}\text { Measurement Point } \\
\text { AF value }\end{array}$ & AF Value & $\%$ Change Compared to Baseline \\
\hline \multicolumn{5}{|l|}{ Left eye } \\
\hline None & Baseline & $0 \mathrm{~h}$ & 0.0166 & 0 \\
\hline Saline & $0-6 \mathrm{~h}$ & $6 \mathrm{~h}$ & 0.0162 & -2.4 \\
\hline None & $6-18 \mathrm{~h}$ & $18 \mathrm{~h}$ & 0.0173 & +4.2 \\
\hline FN3K & $18-24 \mathrm{~h}$ & $24 \mathrm{~h}$ & 0.0077 & -53.9 \\
\hline \multicolumn{5}{|l|}{ Right eye } \\
\hline None & Baseline & $0 \mathrm{~h}$ & 0.0101 & 0 \\
\hline FN3K & $0-6 \mathrm{~h}$ & $6 \mathrm{~h}$ & 0.0084 & -16.4 \\
\hline None & $6-18 \mathrm{~h}$ & $18 \mathrm{~h}$ & 0.0079 & -21.5 \\
\hline Saline & $18-24 \mathrm{~h}$ & $24 \mathrm{~h}$ & 0.0086 & -14.9 \\
\hline
\end{tabular}

\section{Discussion}

Our first preliminary animal experiments showed a color restoration of equine cataractous lenses after ex vivo intravitreal FN3K injection. Furthermore, the extension rate of an equine FN3K-treated lens more than doubled compared to its control-treated counterpart. It is already well known that, according to the classical view as illustrated in Section 2.1, the FN3K enzyme removes ketoamines and consequently prevents the production of AGEs [18]. However, our results also indicate a potential additional role of recombinant FN3K and its cofactors in the breakdown of high molecular mass compounds (AGEs) in cataractous lenses.

Both in vitro FN3K treatment of AGE-modified porcine lens fragments as well as in vivo intravitreal FN3K injection of murine eyes showed a significant reduction of Maillard-type autofluorescence. The latter without provoking a systemic immune response. We also observed a difference in lens geometry between saline- and FN3K-treated murine lenses. It is known that the glycation-induced aggregation and covalent crosslinking of lens crystallins can result in a decrease of natural elasticity and an increase in stiffness [25,26]. Normally the lens capsule together with the cortex, when not under tension of the zonules, causes the lens to assume a more rounded shape [27]. On the histological sections of the murine eye pair, the lens capsule was still present and intact in the lenses of both the FN3K- and saline-treated eyes. Consequently, FN3K did not only decrease the amount of Maillard-type autofluorescence, but also changed geometry in the cortex fibers, which strengthens our hypothesis that the process of non-enzymatic glycation of proteins, such as crystallins can be reversed. Several studies have demonstrated that Maillard reactions by sugars can induce a decrease in the chaperone function of $\alpha$-crystallins [28-30]. Based on our results, we could hypothesize a potential role of FN3K in the restoration of $\alpha$-crystallin chaperone activity. Positive modulation of $\alpha$-crystallin chaperone activity has already been recognized as a possible evading strategy for cataract progression. Estimations have been made that a 10-year delay in cataract incidence can almost halve the number of cataract surgeries [31].

Similar results were obtained on human material. Gel filtration patterns of urea-soluble pooled human lens fractions revealed the presence of high molecular mass compounds, which broke down after FN3K treatment. AF kinetics on cataractous human lens suspen- 
sions revealed a dose- and time-dependent effect of treatment with the active FN3K enzyme, while showing no notable changes for the mutant enzyme. Besides, our data revealed a significant decrease of $\mathrm{AF}$ values after incubation of a cataractous human eye lens with FN3K and a lighter color of the cortex of another cataractous lens. At last, crossover topical treatment of post-mortem human eyes with saline and FN3K containing drops revealed a decrease of AF values when applying FN3K, while only small or negligible changes were noted after topical treatment with saline drops.

In 2010, one in three blind people became blind due to cataracts, and one of six visually impaired people became visually impaired due to cataracts, over $90 \%$ of whom live in low- and middle-income countries [32]. Cost, an insufficient number of ophthalmologists, and low government funding remain significant barriers to relieve the growing cataract burden by surgery alone. In addition to these, postoperative complications (e.g., posterior capsular opacification, endophthalmitis and uncorrected residual refractive error) can occur [33]. As a result, cataracts remains a major public health problem, especially in lowand middle- income countries, and there is a search for a pharmacological intervention that will restore the transparency of the lens. Our preliminary data might be promising for treating cataracts in a more cost-effective way, especially in developing countries where the need for an affordable treatment option rises year by year as people grow older and the prevalence of diabetes mellitus rises. Whereas the pathogenic role of AGEs in the development of cataracts has been well characterized at the molecular level in both normal aging as well as in the diabetic context [9], the unique structure of the lens is also vulnerable to a wide range of other factors: age-related (e.g., carbamoylation, deamidation, thiolation, proteolysis, antioxidant loss, free-radical scavenging) and non-age-related (e.g., genetics, trauma, uveitis, scleritis, radiation and toxic factors) [34,35]. Therefore, it is rather evident that FN3K treatment will not be able to provide an answer to all types of cataracts. Only a subgroup of cataract patients are expected to benefit from the potential therapeutic effects of FN3K.

Furthermore, while FN3K appears to be active against autofluorescent AGEs, we currently do not know its potential effect on non-autofluorescent AGEs. Albeit commercial antibody-based staining protocols for AGEs are available, their applicability is rather limited since AGEs represent a heterogeneous group of compounds and the exact targets of the antibodies have not yet been established [24]. So far, dozens of AGEs have been reported in vivo, with most of them being present at increased levels in cataractous lenses [13]. As an example, the non-fluorescent AGE glucosepane is known to be present to a higher degree in senile cataractous lenses compared to age-matched non-cataractous lenses [30,36]. However, the occurrence of specific AGEs can also depend on the type of cataract. Whereas higher amounts of the fluorescent AGE pentosidine have been found in diabetic cataracts compared to senile cataracts, levels of the non-fluorescent AGE $\mathrm{N}^{\varepsilon}$-carboxymethyllysine have been reported to be rather comparable between the two cataract types [37]. While ongoing diffusion experiments are being conducted to investigate the ocular and lens penetration of FN3K for intravitreal injections as well as for topical eye drops, we could hypothesize a potential role for the lens microcirculation system in the delivery of FN3K molecules within the lens [38,39]. Nevertheless, with aging, the development of a barrier to the transport of molecules within the lens has been reported [40,41]. Such a barrier could complicate an optimal influx of the enzyme within the lens interior. However, we could hypothesize that the destruction of cross-linked AGEs by FN3K has the ability to reduce the viscosity of the diffusion medium (the lens), thereby facilitating its transport within it.

Our study is hampered by several limitations. First of all, experiments in this study have only been performed on human material in vitro or ex vivo. Human clinical trials are indispensable for assessing the clinical validity of our findings. Furthermore, mice were treated with only one injection of FN3K. It can be expected that in the in vivo situation multiple treatment rounds will be necessary to obtain the most optimal results. Besides, it might as well be that after time in humans, crosslinking of the $\beta \gamma$-crystallins recurs 
and treatment should be repeated. At last, the power of our study is hampered by a low number of intact human eye lenses.

Overall, it can be concluded that the FN3K enzyme represents a potential additional treatment option for AGE-related cataract, which can be of special interest to developing countries. While our preliminary results are in need of validation on larger sample sizes and need to be confirmed by human clinical trials, our findings pave the way for future research.

\section{Materials and Methods}

\subsection{Production of Active and Mutant Fructosamine-3-Kinase \\ 4.1.1. Construct Design}

A DNA construct encoding human FN3K (UniProt Q9H479) flanked by an N-terminal His-tag with a caspase-cleavable D-E-V-D site was codon-optimized for P. pastoris (GeneArt, Regensburg, Bavaria, Germany) and cloned into the pKai61 vector [42] for intracellular expression. In light of preclinical experiments with FN3K, a catalytically inactive mutant of the protein would be a valuable asset as a suitable negative control. We, therefore, produced a mutant human FN3K carrying a K41L substitution (FN3K-K41L) in the putative F-V-K catalytic triad. Plasmids encoding codon-optimized FN3K-K41L flanked by an N-terminal His-tag with a caspase-cleavable D-E-V-D site were created by introducing synthetic DNA fragments into a Golden Gate assembly-based modular cloning system [43]. Electrocompetent cells, prepared according to a condensed protocol [44], were transformed with the PmeI-linearized vectors.

\subsubsection{Protein Production and Purification}

$P$. pastoris cultures of up to $2 \mathrm{~L}$ were grown in baffled shake flasks with a maximum of $250 \mathrm{~mL}$ culture per $2 \mathrm{~L}$ flask. Cells were grown for $48 \mathrm{~h}$ at $28{ }^{\circ} \mathrm{C}$ in a BMGY medium (100 mM potassium phosphate $\mathrm{pH} 6,2 \% \mathrm{w} / \mathrm{v}$ peptone, $1 \% \mathrm{w} / \mathrm{v}$ yeast extract, $1 \% \mathrm{w} / \mathrm{v}$ yeast nitrogen base without amino acids and 1\% glycerol) containing glycerol as the sole carbon source, and subsequently transferred to BMMY medium (100 mM potassium phosphate $\mathrm{pH} 6,2 \% \mathrm{w} / \mathrm{v}$ peptone, $1 \% \mathrm{w} / \mathrm{v}$ yeast extract, $1 \% \mathrm{w} / \mathrm{v}$ yeast nitrogen base without amino acids and 1\% methanol), which induced recombinant protein expression by substitution of glycerol for methanol. After 48 hours of incubation at $28^{\circ} \mathrm{C}$, cell pellets were harvested by centrifugation at $400 \times g$. Pellets were resuspended in isolation buffer (50 mM sodium phosphate $\mathrm{pH} 8.0,5 \%$ glycerol, $1 \mathrm{mM}$ EDTA, and $1 \mathrm{mM}$ DTT) and ruptured via mechanical homogenization using $0.5 \mathrm{~mm}$ acid-washed glass beads in a continuous mode DYNO-MILL homogenizer (GlenMills, Clifton, New Jersey, USA). The pH of the obtained lysate was adjusted to $\mathrm{pH} 8.0$ and $2 \mathrm{mM} \mathrm{MgSO}_{4}$ was added. After incubation at $4{ }^{\circ} \mathrm{C}$ while stirring for $30 \mathrm{~min}$, the supernatant was cleared by centrifugation (30 min at $48,000 \times g$ at $\left.4{ }^{\circ} \mathrm{C}\right)$ or filtration $(0.22 \mu \mathrm{m}$ Steritop filter). The cleared supernatant was loaded onto a HisTrap IMAC column (GE Healthcare, Chicago, Illinois, USA) equilibrated with isolation buffer and the bound protein was eluted by increasing the imidazole concentration to $400 \mathrm{mM}$ while lowering the $\mathrm{NaCl}$ concentration to $20 \mathrm{mM}$. IMAC-eluted fractions were then pooled for injection on a Superdex75 Hiload 16/600 column (GE Healthcare) equilibrated with FN3K sample buffer $(20 \mathrm{mM}$ Tris- $\mathrm{HCl} \mathrm{pH} 8.0,150 \mathrm{mM} \mathrm{NaCl}$ and $1 \mathrm{mM}$ DTT). Fractions containing the protein of interest were pooled, their protein concentration determined spectroscopically and their kinase activity (or lack thereof, for FN3K-K41L) was assayed in vitro using the phosphatase-coupled Universal Kinase Activity Kit (R\&D Systems, Minneapolis, Minnesota, USA) with a 1-deoxy-1-morpholino-D-fructose (DMF) acceptor substrate [14]. Briefly, dilution series of FN3K and FN3K-K41L in reaction buffer (25 mM HEPES, $150 \mathrm{mM} \mathrm{NaCl}, 10 \mathrm{mM} \mathrm{MgCl}_{2}$ and $10 \mathrm{mM} \mathrm{CaCl}_{2}, \mathrm{pH}$ 7.0) were incubated with $2 \mathrm{mM}$ DMF in presence or absence of $0.4 \mathrm{mM}$ ATP. After $30 \mathrm{~min}$ incubation at $37^{\circ} \mathrm{C}$, phosphatase CD39L2 was added $(2 \mathrm{ng} / \mu \mathrm{L})$ and the release of inorganic phosphate (proportional to the amount of ADP generated during the kinase reaction) was detected at $595 \mathrm{~nm}$ using malachite green coloring reagents. After subtraction of negative control (ATP absent) signal, phosphate release as compared to an inorganic phosphate standard 
curve was quantified for each well. The activity of FN3K and FN3K-K41L was derived from linear regression within the linear range of the dose-response curve. The protein was further characterized on SDS-PAGE and Western blot using either a DyLight800-coupled anti-His antibody or a polyclonal rabbit anti-FN3K antibody (Life Technologies, Carlsbad, California, USA) and a secondary DyLight680-coupled goat anti-rabbit antibody. Purified proteins were aliquoted, snap-frozen in liquid nitrogen, and stored at $-80^{\circ} \mathrm{C}$.

\subsection{Ex Vivo Intravitreal FN3K Injection of Equine Eyes}

As a first preliminary experiment, equine $(n=3)$ eye pairs were eviscerated from fresh cadavers and transported to the lab on ice before injection. For each eye pair, one eye was intravitreally injected with $50 \mu \mathrm{L}$ of an FN3K solution $(8.33 \mu \mathrm{g} / \mathrm{mL}$ FN3K, $3.33 \mathrm{mM}$ ATP (Sigma-Aldrich, St. Louis, Missouri, USA), and $1.33 \mathrm{mM} \mathrm{MgCl}_{2}$ (Sigma-Aldrich)) and the other eye with $50 \mu \mathrm{L}$ of a saline solution. Before injection, both eyes of the same animal were evaluated as equally affected by an expert ophthalmologist. After incubation in saline for $24 \mathrm{~h}$ at $37^{\circ} \mathrm{C}$, lenses were removed from the intact eye and macroscopic changes of the equine lenses were assessed. In addition, mechanical properties were measured and compared between an FN3K-treated equine lens and its saline-treated counterpart. Mechanical analysis was performed on an LFPlus Universal material tester (Lloyd Materials testing, Bognor Regis, UK) with a ball probe of $4.45 \mathrm{~mm}$ in diameter and an indentation speed of $25 \mathrm{~mm} / \mathrm{min}$. A lower force limit of $0.1 \mathrm{~N}$ was set as the zero-indentation point for the tissue. The tissue was indented by a descending ball probe, to which the central hole was aligned. A load cell of $10 \mathrm{~N}$ was used and a maximum force of $5 \mathrm{~N}$ was chosen. A five-cycle indentation was performed to exclude the hysteresis effect of the tissue. The stiffness parameter $(\mathrm{N} / \mathrm{mm})$, the slope of the linear section of the indentation-load curve, was determined.

\subsection{Autofluorescence Measurement of AGEs}

As described previously [24,45], AGEs were quantified based on Maillard-type autofluorescence (AF) measurements (excitation $365 \mathrm{~nm}$, emission 390-700 nm) using a Flame miniature spectrometer (FLAME-S-VIS-NIR-ES, 350-1000 nm, Ocean Optics, Dunedin, Florida, USA) equipped with a high-power LED light source (365 nm, Ocean Optics) and a reflection probe (QR400-7-VIS-BX, Ocean Optics). Measurements were averaged over 128 scans. AF values were calculated by dividing the average light intensity emitted per $\mathrm{nm}$ for the $407 \mathrm{~nm}$ to $677 \mathrm{~nm}$ range by the average light intensity per nm over the $342 \mathrm{~nm}$ to $407 \mathrm{~nm}$ range. Analysis of potential interfering agents such as solutions containing ATP (3-100 mM), ADP (12.5 mM, Sigma-Aldrich) and NADPH (10 mM, Sigma-Aldrich) did not reveal notable AF using our setup (data not shown).

\subsection{FN3K Treatment of AGE-Modified Porcine Lenses}

Porcine eyes $(n=15)$ were obtained from a local abattoir and lenses were isolated through dissection by a trained ophthalmologist within $12 \mathrm{~h}$ post mortem. The lenses were stored at $-20^{\circ} \mathrm{C}$ until further processing. Fragments of each lens were added to wells of a black 96-well plate suitable for fluorescence measurements until complete coverage of the bottom was obtained (FluoroNunc PolySorp, Thermo Fisher Scientific, Massachusetts, USA). Fluorescence measurements were executed at baseline for each lens fragment at a fixed distance and straight angle. Since glycolaldehyde is a widely known compound to alter proteins by AGE formation, AGE modification was performed by incubation of the lens fragments with $20 \mu \mathrm{L}$ of $25 \mathrm{mM}$ glycolaldehyde dimer (crystalline form, SigmaAldrich) in phosphate buffered saline (PBS) for $3 \mathrm{~h}$ at $37^{\circ} \mathrm{C}$ [15]. After incubation, lens fragments were stored for $72 \mathrm{~h}\left(4^{\circ} \mathrm{C}\right)$ to ensure completion of the chemical reaction. Subsequently, in vitro deglycation of AGE-modified lens fragments $(n=11)$ was initiated using $20 \mu \mathrm{L}$ of a solution containing $125 \mu \mathrm{g} / \mathrm{mL}$ FN3K and a fixed amount of ATP $(12.5 \mathrm{mM})$ and $\mathrm{MgCl}_{2}(5 \mathrm{mM})$ in phosphate buffered saline (PBS). The remaining lens fragments $(n=4)$ were control treated with $20 \mu \mathrm{L}$ of a solution containing the cofactors ATP and $\mathrm{MgCl}_{2}$ 
solely. The wells were incubated for 3 hours at $37^{\circ} \mathrm{C}$. Fluorescence measurements were performed immediately after the addition of the FN3K or control solution and repeated after each subsequent hour.

\subsection{In Vivo Intravitreal FN3K Injection of Murine Eyes}

To investigate the effect of FN3K treatment on murine lenses, ob/ob mice $(n=20$, male/female: 8/12, mean age: $24.4 \pm 1.4$ weeks, BTBR.Cg-Lepob/WiscJ, stock no. 004824, The Jackson Laboratory, Bar Harbor, ME, USA) were anesthetized during surgical procedures with inhalation anesthesia (isoflurane $5 \%$ ). Both eyes of the same animal were injected with a 32-gauge needle, one with $5 \mu \mathrm{L}$ FN3K $(8.33 \mu \mathrm{g} / \mathrm{mL}$ FN3K, $3.33 \mathrm{mM}$ ATP and $1.33 \mathrm{mM} \mathrm{MgCl}_{2}$ ) and one with $5 \mu \mathrm{L}$ saline solution. Eyelids were gently moved backwards with a pincet so that injection could be performed just before the equator of the globe with the tip of the needle directed towards the center of the globe, in order not to touch the lens or the retina [46]. Twenty-four hours later, the mice were sacrificed, both eyes were enucleated and the lenses removed. AF measurements were performed on the intact lenses. Afterwards, the geometry of the lenses was evaluated macroscopically. The saline- and FN3K-treated lenses of one mouse were subjected to standard histological examination by a specialized pathologist. Two-micrometer sections were cut, stained with HE, periodic acid Schiff, Jones' methenamine silver and Masson trichrome, and finally cover-slipped.

\subsection{Serum Cytokine Levels of FN3K-Treated Mice}

Ob/ob ( $n=35$, male/female: 16/19, mean age: $26.5 \pm 2.9$ weeks) and WT ( $n=20$, male/female: $8 / 12$, mean age: $27.6 \pm 3.3$ weeks) mice were anesthetized and injected intravitreously with $5 \mu \mathrm{L}$ of the FN3K solution as described above. Using commercial ELISA kits (Ready-SET-Go! ELISA-kits, eBioscience, San Diego, CA, USA), the presence of IL-2, TNF $\alpha$, and IFN $\gamma$ was determined in undiluted serum and expressed as $\mathrm{pg} / \mathrm{mL}$. Measurements were performed $24 \mathrm{~h}, 4$ days or 7 days after treatment. In addition, cytokine levels in $3 \mathrm{ob} / \mathrm{ob}$ and $2 \mathrm{WT}$ mice (aged 24 weeks) were measured as negative controls (non-treated).

\subsection{Human Experiments}

4.7.1. Gel Filtration of Human Cataractous Lens Fractions before and after FN3K Treatment

Human lens fragments were obtained following phacoemulsification during cataract surgery from 10 patients. After surgery, the conservation fluid containing the lens fragments was centrifuged $\left(1902 \times g, 5 \mathrm{~min}, 21^{\circ} \mathrm{C}\right)$ and the supernatant was removed. Afterwards, pooled fragments $(20 \mathrm{mg})$ were incubated for $3 \mathrm{~h}$ at $37^{\circ} \mathrm{C}$ in $200 \mu \mathrm{L}$ of a solution containing $125 \mu \mathrm{g} / \mathrm{mL}$ FN3K and a fixed amount of ATP $(12.5 \mathrm{mM})$ and $\mathrm{MgCl}_{2}(5 \mathrm{mM})$ in PBS ( $\mathrm{pH}$ 7.4). Untreated pooled fragments $(20 \mathrm{mg})$ were stored under the same conditions. Since it is well known that cataracts are associated with strong increases in water-insoluble proteins [47], urea-soluble (water-insoluble) proteins from both the untreated and treated lens fragments were extracted in $6 \mathrm{M}$ urea in PBS for $4 \mathrm{~h}$ at $4{ }^{\circ} \mathrm{C}$ in Eppendorf SafeLock Tubes (Hamburg, Germany). After centrifugation $\left(16,000 \times g, 10 \mathrm{~min}, 21^{\circ} \mathrm{C}\right)$, the supernatant was retained for gel filtration. Gel filtration of untreated and FN3K-treated lens fragments was carried out on a chromatography column (length: $60 \mathrm{~cm}$, diameter: $15 \mathrm{~mm}$ ) packed with Sephadex G-25 ${ }^{\circledR}$ Fine resin (Sigma-Aldrich) in order to assess the molecular mass of fructose containing lens compounds such as AGEs. Following fractionation, individual fractions were photometrically tested using the resorcinol- $\mathrm{HCl}$ (Seliwanoff) reaction, a well-known color reaction for ketoses [48]. In this reaction, a $50 \mu \mathrm{L}$ sample was added to $100 \mu \mathrm{L}$ resorcinol (9 mM, Sigma-Aldrich) and $1 \mathrm{~mL}$ hydrochloric acid (9 M, Sigma-Aldrich). Following incubation in a boiling water bath for $5 \mathrm{~min}$, the developed color was read photometrically in a standard $10 \mathrm{~mm}$ cuvette at $488 \mathrm{~nm}$. 


\subsubsection{Kinetics of FN3K Treatment}

Human lens fragments were obtained following phacoemulsification during cataract surgery from 50 patients. After surgery, the conservation fluid containing the lens fragments was centrifuged ( $3000 \mathrm{rpm}, 5 \mathrm{~min}, 21^{\circ} \mathrm{C}$ ) and the supernatant was removed. Pooled fragments were added to wells of a black 96-well plate until complete coverage of the bottom was obtained. Subsequently, $20 \mu \mathrm{L}$ of a solution containing different concentrations of active or mutant FN3K $(125 \mu \mathrm{g} / \mathrm{mL}, 62.5 \mu \mathrm{g} / \mathrm{mL}$ and $31.8 \mu \mathrm{g} / \mathrm{mL})$ and a fixed amount of ATP $(12.5 \mathrm{mM})$ and $\mathrm{MgCl}_{2}(5 \mathrm{mM})$ in PBS were added to the wells. Besides, a second experiment was performed in a lower concentration range of active FN3K $(12.5 \mu \mathrm{g} / \mathrm{mL}$, $6.25 \mu \mathrm{g} / \mathrm{mL}$ and $1.25 \mu \mathrm{g} / \mathrm{mL}$ ). The wells were incubated for $3 \mathrm{~h}$ at $37^{\circ} \mathrm{C}$. Fluorescence measurements were performed at baseline and after each subsequent hour. All experiments were performed in triplo.

\subsubsection{FN3K Treatment of Intact Eye Lenses}

Ex vivo FN3K treatment was performed on the intact left eye lens of a 79-year-old patient with-in the ophthalmological history cataract and an occlusion of the left arteria ophthalmica. The lens from the enucleated human eye was isolated through dissection by a trained ophthalmologist within $24 \mathrm{~h}$ post mortem and stored at $4{ }^{\circ} \mathrm{C}$ in an RPMI1640 medium (Thermo Fisher Scientific) until analysis. The experiment was started by removing the RPMI medium and washing the lens with $5 \mathrm{~mL}$ PBS solution. Fluorescence measurements were performed at baseline at 15 different measurement locations each on the ventral and dorsal surface of the lens. Subsequently, the whole lens was deglycated by incubation during $20 \mathrm{~h}$ at $37^{\circ} \mathrm{C}$ in $2 \mathrm{~mL}$ of a solution containing $1.6 \mu \mathrm{g} / \mathrm{mL}$ FN3K and a fixed amount of ATP $(2.5 \mathrm{mM})$ and $\mathrm{MgCl}_{2}(1 \mathrm{mM})$ in PBS. After incubation, the lens was washed 5 times with PBS and fluorescence measurements were repeated. In addition, an intact cataractous eye lens of an 89-year-old patient was enucleated within $24 \mathrm{~h}$ post mortem and deglycated by incubation during $3 \mathrm{~h}$ at $37^{\circ} \mathrm{C}$ in $2 \mathrm{~mL}$ of the FN3K solution described above. In addition, a cataractous eye lens originating from another patient was control-treated with a saline solution. Digital images were acquired in a portable LED photocube (Caruba, Beilen, the Netherlands) at baseline and after each subsequent half hour (FN3K treatment) or hour (control treatment) using a Canon EOS 2000D digital camera with EF-S18-55mm f/3.5-5.6 IS II zoom lens (Canon Inc., Tokio, Japan). ImageJ v1.8.0 (NIH, http:/ / rsb.info.nih.gov/ij, accessed on 3 October 2019) was employed for subsequent image analysis.

\subsubsection{Topical Treatment of Post-Mortem Eyes}

A crossover topical treatment experiment with either saline- or FN3K-containing drops was performed on the enucleated post mortem eyes of a 78-year-old patient with cataractous lenses. The patient's left eye was treated with saline-containing drops until complete coverage of the eye's surface was reached. The procedure was repeated after each subsequent hour for 6 consecutive hours. Subsequently, the eye was stored overnight $(12 \mathrm{~h}$, $4{ }^{\circ} \mathrm{C}$ ). Afterwards, a crossover treatment was performed by applying FN3K-containing drops. Again, the procedure was repeated each hour for 6 consecutive hours. The patient's right eye was processed similarly; however, a reverse order of treatment was applied. AF measurements were performed at a fixed position through the cornea of the intact eyes at baseline, after 6,18 , and $24 \mathrm{~h}$.

\subsection{Statistical Analysis}

Statistical analyses was performed using GraphPad Prism version 8.4.3. (San Diego, CA, USA) Normality of the data was assessed by the Shapiro-Wilk test. Non-normally distributed data are presented as median with the interquartile range (IQR), normally distributed data as mean \pm standard deviation (SD). For non-normally distributed data, unpaired differences between 2 groups were assessed using the Mann-Whitney U test and paired differences using the Wilcoxon matched-pairs signed rank test. For normally 
distributed data, pairwise comparisons between more than 2 groups were accomplished with repeated measures one-way analysis of variance (ANOVA). Subsequently, individual comparisons between 2 groups were performed with paired $t$ tests. A $p$ value $<0.05$ was considered a priori to be statistically significant.

\section{Patents}

"Compositions for use to treat cataract" patent filed at the European Patent Office. Priority date: 30.01.2018, international application number: PCT/EP2019/051961, international publication number: WO 2019/149648 A1, international publication date: 08.08.2019.

Author Contributions: Conceptualization, E.V.A. and J.R.D.; Data curation, S.D.B.; Formal analysis, S.D.B., L.v.S., J.H., F.D.S. and E.V.A.; Funding acquisition, E.V.A. and J.R.D.; Investigation, S.D.B., J.H., E.V.A. and J.R.D.; Methodology, S.D.B., E.V.A. and J.R.D.; Project administration, E.V.A. and J.R.D.; Resources, I.E., W.D., C.V.d.B., M.H., N.B., N.C., E.V.A. and J.R.D.; Supervision, E.V.A. and J.R.D.; Visualization, S.D.B.; Writing-original draft, S.D.B. and E.V.A.; Writing-review and editing, S.D.B., L.v.S., J.H., F.D.S., I.E., W.D., C.V.d.B., M.H., N.B., M.S., N.C., E.V.A. and J.R.D. All authors have read and agreed to the published version of the manuscript.

Funding: This work was supported by an IOF grant number F2017/IOF-Advanced/089.

Institutional Review Board Statement: The study was conducted according to the guidelines of the Declaration of Helsinki, and approved by the Ethics Committee of Ghent University (Belgian registration number B670201838497, 31 October 2018). The animal experiments were approved by the Ethics Committee for Animal Research at Ghent University (ECD 16/38, 6 September 2016) and followed the Principles of Laboratory Animal Care.

Informed Consent Statement: Not applicable.

Data Availability Statement: The data that support the findings of this study are available from the corresponding author, upon reasonable request.

Conflicts of Interest: The funders had no role in the design of the study; in the collection, analyses, or interpretation of data; in the writing of the manuscript, or in the decision to publish the results.

$\begin{array}{ll}\text { Abbreviations } \\ \text { ADP } & \text { Adenosine diphosphate } \\ \text { AF } & \text { Autofluorescence } \\ \text { AGEs } & \text { Advanced glycation end products } \\ \text { ATP } & \text { Adenosine triphosphate } \\ \text { BMMY } & \text { Buffered methanol-complex medium } \\ \text { DMF } & \text { 1-deoxy-1-morpholino-D-fructose } \\ \text { DTT } & \text { Dithiothreitol } \\ \text { EDTA } & \text { Ethylenediaminetetraacetic acid } \\ \text { ELISA } & \text { Enzyme-linked immunosorbent assay } \\ \text { FN3K } & \text { Fructosamine-3-kinase } \\ \text { HE } & \text { Hematoxylin and eosin } \\ \text { IMAC } & \text { Immobilized metal affinity chromatography } \\ \text { IQR } & \text { Interquartile range } \\ \text { NADPH } & \text { Nicotinamide adenine dinucleotide phosphate } \\ \text { PBS } & \text { Phosphate buffered saline } \\ \text { SDS-PAGE } & \text { Sodium dodecyl sulphate-polyacrylamide gel electrophoresis } \\ \text { WT } & \text { Wild-type }\end{array}$




\section{Appendix A. Serum Cytokine Levels of FN3K-Treated Mice}
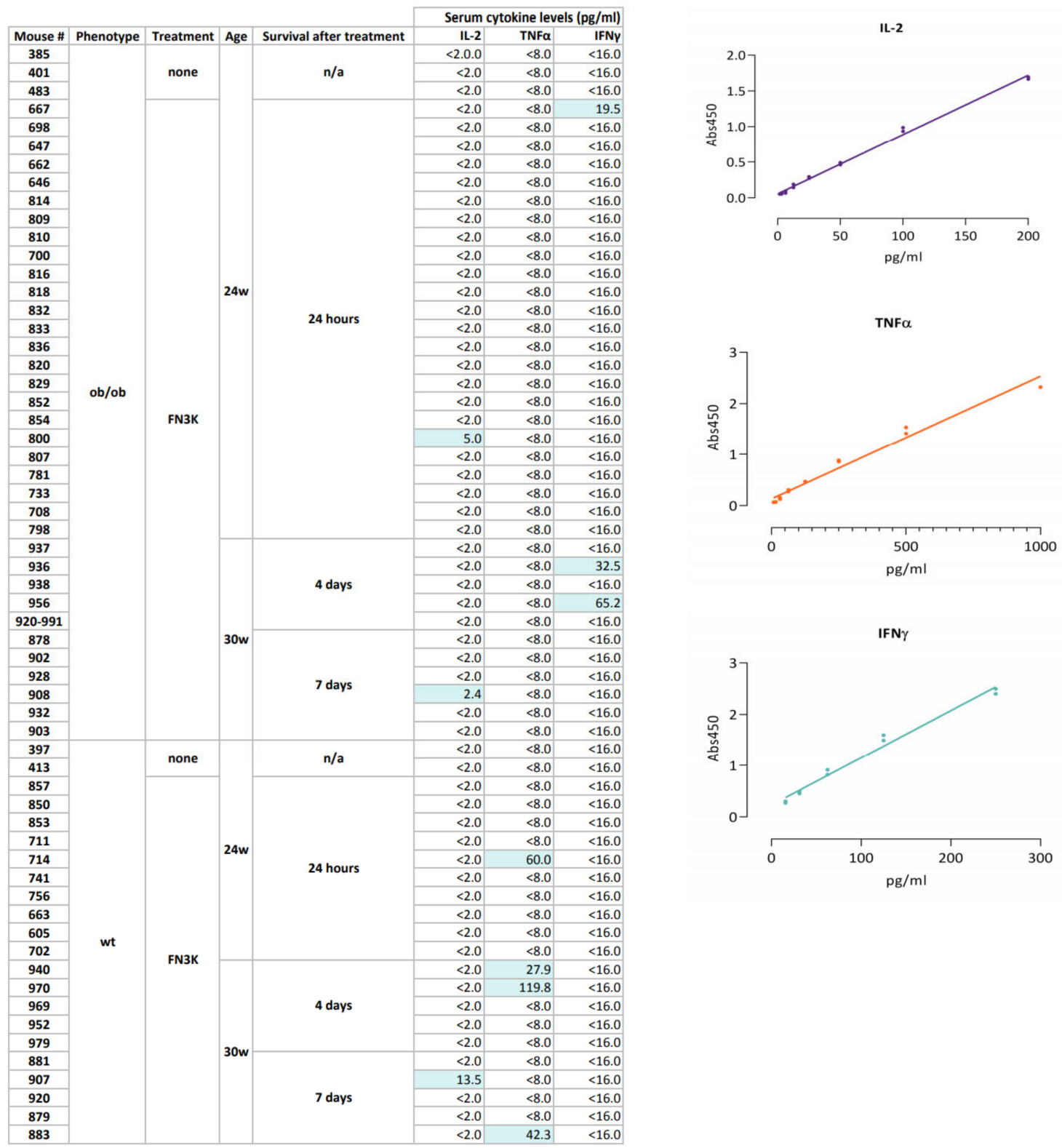

Figure A1. Serum ELISA results of IL-2, TNF $\alpha$ and IFN $\gamma$ in non-treated $o b / o b$ and WT mice $(n=5)$ and FN3K-treated mice $(n=55)$. In all non-treated mice serum levels of IL-2, TNF $\alpha$ and IFN $\gamma$ were below detection limits $(2 \mathrm{pg} / \mathrm{mL}$, $8 \mathrm{pg} / \mathrm{mL}$ and $16 \mathrm{pg} / \mathrm{mL}$, respectively). In a large majority of FN3K-treated mice (45 out of 55), levels of these 3 cytokines were below detection limits as well. In several serum samples (10 out of 55), one of the three cytokines tested for was upregulated. However, cytokine levels were not consistently high within treatment groups and in general were very low (below $120 \mathrm{pg} / \mathrm{mL}$ ). From this, we could conclude that intravitreal injection of a therapeutic FN3K mixture did not consistently provoke a systemic immune response. Calibration curves of IL-2, TNF $\alpha$ and IFN $\gamma$ are illustrated on the right side. 


\section{Appendix B}

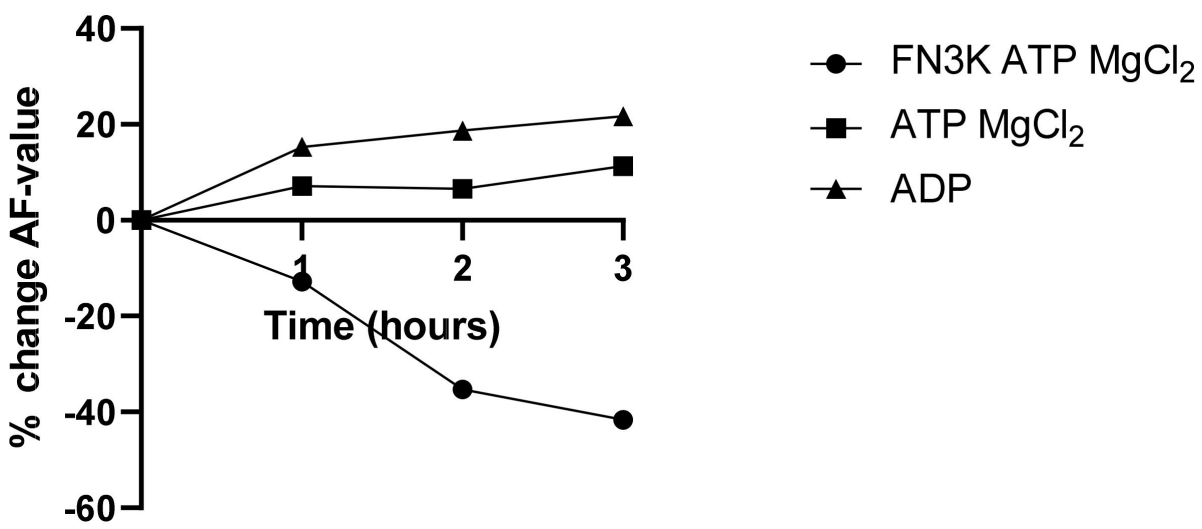

Figure A2. Time-dependent changes (\%) in autofluorescence (AF) values after treatment of a cataractous human lens suspension (different suspension as the one used in Section 4.7.2 "Kinetics of FN3K treatment") with $20 \mu \mathrm{L}$ of a solution containing fructosamine-3-kinase (FN3K, $125 \mu \mathrm{g} / \mathrm{mL}$ ) and its cofactors ATP $(12.5 \mathrm{mM})$ and $\mathrm{MgCl}_{2}(5 \mathrm{mM})$ in PBS, (2) the cofactors solely and (3) a solution containing ADP solely $(12.5 \mathrm{mM})$. The experiments were performed in duplicate using the same setup as described in Section 4.7.2. While clear decreases in AF values were observed for the FN3K enzyme, slight increases in AF values were noticed for the solutions containing $\mathrm{ATP} / \mathrm{MgCl}_{2}$ and ADP. Based on these results, we could conclude that neither the added ATP nor the ADP that was not released by the mutant enzyme was responsible for the observed decreases in autofluorescence after FN3K treatment in our experiments.

\section{References}

1. Liu, Y.-C.; Wilkins, M.; Kim, T.; Malyugin, B.; Mehta, J.S. Cataracts. Lancet 2017, 390, 600-612. [CrossRef]

2. World Health Organization. Blindness and Vision Impairment 2019. Available online: https://www.who.int/news-room/factsheets/detail/blindness-and-visual-impairment (accessed on 8 July 2020).

3. World Health Organization. Priority Eye Diseases (2020). Available online: http://www.who.int/blindness/causes/priority/en/ index1.html (accessed on 8 July 2020).

4. Stitt, A.W. The Maillard Reaction in Eye Diseases. Ann. N. Y. Acad. Sci. 2005, 1043, 582-597. [CrossRef]

5. Shiels, A.; Hejtmancik, J.F. Genetics of Human Cataract. Clin. Genet. 2013, 84, 120-127. [CrossRef]

6. Sergi, D.; Boulestin, H.; Campbell, F.M.; Williams, L.M. The Role of Dietary Advanced Glycation End Products in Metabolic Dysfunction. Mol. Nutr. Food Res. 2021, 65, e1900934. [CrossRef]

7. Tessier, F.J. The Maillard Reaction in the Human Body. The Main Discoveries and Factors That Affect Glycation. Pathol. Biol. 2010, 58, 214-219. [CrossRef]

8. Ruiz, H.H.; Ramasamy, R.; Schmidt, A.M. Advanced Glycation End Products: Building on the Concept of the "Common Soil" in Metabolic Disease. Endocrinology 2020, 161. [CrossRef]

9. Bejarano, E.; Taylor, A. Too Sweet: Problems of Protein Glycation in the Eye. Exp. Eye Res. 2019, 178, 255-262. [CrossRef]

10. Chaudhuri, J.; Bains, Y.; Guha, S.; Kahn, A.; Hall, D.; Bose, N.; Gugliucci, A.; Kapahi, P. The Role of Advanced Glycation End Products in Aging and Metabolic Diseases: Bridging Association and Causality. Cell Metab. 2018, 28, 337-352. [CrossRef] [PubMed]

11. Dillon, J.; Skonieczna, M.; Mandal, K.; Paik, D. The Photochemical Attachment of the O-Glucoside of 3-Hydroxykynurenine to Alpha-Crystallin: A Model for Lenticular Aging. Photochem. Photobiol. 1999, 69, 248-253. [CrossRef] [PubMed]

12. Javadi, M.-A.; Zarei-Ghanavati, S. Cataracts in Diabetic Patients: A Review Article. J. Ophthalmic. Vis. Res. 2008, 3, 52-65.

13. Smuda, M.; Henning, C.; Raghavan, C.T.; Johar, K.; Vasavada, A.R.; Nagaraj, R.H.; Glomb, M.A. Comprehensive Analysis of Maillard Protein Modifications in Human Lenses: Effect of Age and Cataract. Biochemistry 2015, 54, 2500-2507. [CrossRef]

14. Delpierre, G.; Collard, F.; Fortpied, J.; Van Schaftingen, E. Fructosamine 3-Kinase Is Involved in an Intracellular Deglycation Pathway in Human Erythrocytes. Biochem. J. 2002, 365, 801-808. [CrossRef]

15. Avemaria, F.; Carrera, P.; Lapolla, A.; Sartore, G.; Chilelli, N.C.; Paleari, R.; Ambrosi, A.; Ferrari, M.; Mosca, A. Possible Role of Fructosamine 3-Kinase Genotyping for the Management of Diabetic Patients. Clin. Chem. Lab. Med. 2015, 53, 1315-1320. [CrossRef] [PubMed]

16. Conner, J.R.; Beisswenger, P.J.; Szwergold, B.S. The Expression of the Genes for Fructosamine-3-Kinase and Fructosamine-3Kinase-Related Protein Appears to Be Constitutive and Unaffected by Environmental Signals. Biochem. Biophys. Res. Commun. 2004, 323, 932-936. [CrossRef] [PubMed] 
17. Van Schaftingen, E.; Collard, F.; Wiame, E.; Veiga-da-Cunha, M. Enzymatic Repair of Amadori Products. Amino Acids 2012, 42, 1143-1150. [CrossRef]

18. Dunmore, S.J.; Al-Derawi, A.S.; Nayak, A.U.; Narshi, A.; Nevill, A.M.; Hellwig, A.; Majebi, A.; Kirkham, P.; Brown, J.E.; Singh, B.M. Evidence That Differences in Fructosamine-3-Kinase Activity May Be Associated With the Glycation Gap in Human Diabetes. Diabetes 2018, 67, 131-136. [CrossRef] [PubMed]

19. Sartore, G.; Ragazzi, E.; Burlina, S.; Paleari, R.; Chilelli, N.C.; Mosca, A.; Avemaria, F.; Lapolla, A. Role of Fructosamine-3-Kinase in Protecting against the Onset of Microvascular and Macrovascular Complications in Patients with T2DM. BMJ Open Diabetes Res. Care 2020, 8. [CrossRef]

20. Kishabongo, A.S.; Katchunga, P.; Cikomola, J.C.; De Somer, F.M.; De Buyzere, M.L.; Speeckaert, M.M.; Delanghe, J.R. The Presence of Fructosamine in Human Aortic Valves Is Associated with Valve Stiffness. J. Clin. Pathol. 2016, 69, 772-776. [CrossRef]

21. Jurgeleviciene, I.; Stanislovaitiene, D.; Tatarunas, V.; Jurgelevicius, M.; Zaliuniene, D. Assessment of Absorption of Glycated Nail Proteins in Patients with Diabetes Mellitus and Diabetic Retinopathy. Medicina 2020, 56, 658. [CrossRef]

22. Coopman, R.; Van de Vyver, T.; Kishabongo, A.S.; Katchunga, P.; Van Aken, E.H.; Cikomola, J.; Monteyne, T.; Speeckaert, M.M.; Delanghe, J.R. Glycation in Human Fingernail Clippings Using ATR-FTIR Spectrometry, a New Marker for the Diagnosis and Monitoring of Diabetes Mellitus. Clin. Biochem. 2017, 50, 62-67. [CrossRef]

23. De Bruyne, S.; Van Dorpe, J.; Himpe, J.; Van Biesen, W.; Delanghe, S.; Speeckaert, M.M.; Delanghe, J.R. Detection and Characterization of a Biochemical Signature Associated with Diabetic Nephropathy Using Near-Infrared Spectroscopy on Tissue Sections. J. Clin. Med. 2019, 8, 1022. [CrossRef]

24. De Bruyne, S.; Vandenbroecke, C.; Vrielinck, H.; Khelifi, S.; De Wever, O.; Bracke, K.; Huizing, M.; Boston, N.; Himpe, J.; Speeckaert, M.; et al. Fructosamine-3-Kinase as a Potential Treatment Option for Age-Related Macular Degeneration. J. Clin. Med. 2020, 9, 2869. [CrossRef]

25. Truscott, R.J.W.; Zhu, X. Presbyopia and Cataract: A Question of Heat and Time. Prog. Retin. Eye Res. 2010, 29, 487-499. [CrossRef]

26. Stitt, A.W. Advanced Glycation: An Important Pathological Event in Diabetic and Age Related Ocular Disease. Br. J. Ophthalmol. 2001, 85, 746-753. [CrossRef]

27. Forrester, J.V.; Dick, A.D.; McMenamin, P.G.; Roberts, F.; Pearlman, E. Chapter 1-Anatomy of the eye and orbit. Eye Basic Sci. Pract. 2002, 2, 66-90. [CrossRef]

28. Kumar, P.A.; Kumar, M.S.; Reddy, G.B. Effect of Glycation on Alpha-Crystallin Structure and Chaperone-like Function. Biochem. J. 2007, 408, 251-258. [CrossRef] [PubMed]

29. Bhattacharyya, J.; Shipova, E.V.; Santhoshkumar, P.; Sharma, K.K.; Ortwerth, B.J. Effect of a Single AGE Modification on the Structure and Chaperone Activity of Human AlphaB-Crystallin. Biochemistry 2007, 46, 14682-14692. [CrossRef]

30. Nagaraj, R.H.; Linetsky, M.; Stitt, A.W. The Pathogenic Role of Maillard Reaction in the Aging Eye. Amino Acids 2012, 42, 1205-1220. [CrossRef] [PubMed]

31. Kumar, P.A.; Reddy, G.B. Modulation of $\alpha$-Crystallin Chaperone Activity: A Target to Prevent or Delay Cataract? IUBMB Life 2009, 61, 485-495. [CrossRef]

32. Khairallah, M.; Kahloun, R.; Bourne, R.; Limburg, H.; Flaxman, S.R.; Jonas, J.B.; Keeffe, J.; Leasher, J.; Naidoo, K.; Pesudovs, K.; et al. Number of People Blind or Visually Impaired by Cataract Worldwide and in World Regions, 1990 to 2010. Invest Ophthalmol. Vis. Sci. 2015, 56, 6762-6769. [CrossRef] [PubMed]

33. Chan, E.; Mahroo, O.A.R.; Spalton, D.J. Complications of Cataract Surgery. Clin. Exp. Optom. 2010, 93, 379-389. [CrossRef] [PubMed]

34. Michael, R.; Bron, A.J. The Ageing Lens and Cataract: A Model of Normal and Pathological Ageing. Philos. Trans. R. Soc. Lond. B Biol. Sci. 2011, 366, 1278-1292. [CrossRef]

35. Gupta, V.B.; Rajagopala, M.; Ravishankar, B. Etiopathogenesis of Cataract: An Appraisal. Indian J. Ophthalmol. 2014, 62, 103-110. [CrossRef] [PubMed]

36. Puttaiah, S.; Zhang, Y.; Pilch, H.A.; Pfahler, C.; Oya-Ito, T.; Sayre, L.M.; Nagaraj, R.H. Detection of Dideoxyosone Intermediates of Glycation Using a Monoclonal Antibody: Characterization of Major Epitope Structures. Arch. Biochem. Biophys. 2006, 446, 186-196. [CrossRef]

37. Lyons, T.J.; Silvestri, G.; Dunn, J.A.; Dyer, D.G.; Baynes, J.W. Role of Glycation in Modification of Lens Crystallins in Diabetic and Nondiabetic Senile Cataracts. Diabetes 1991, 40, 1010-1015. [CrossRef]

38. Schey, K.L.; Petrova, R.S.; Gletten, R.B.; Donaldson, P.J. The Role of Aquaporins in Ocular Lens Homeostasis. Int. J. Mol. Sci. 2017, 18, 2693. [CrossRef] [PubMed]

39. Vaghefi, E.; Donaldson, P.J. The Lens Internal Microcirculation System Delivers Solutes to the Lens Core Faster than Would Be Predicted by Passive Diffusion. Am. J. Physiol. Regul. Integr. Comp. Physiol. 2018, 315, R994-R1002. [CrossRef]

40. Korlimbinis, A.; Berry, Y.; Thibault, D.; Schey, K.L.; Truscott, R.J.W. Protein Aging: Truncation of Aquaporin 0 in Human Lens Regions Is a Continuous Age-Dependent Process. Exp. Eye Res. 2009, 88, 966-973. [CrossRef]

41. Truscott, R.J. Age-Related Nuclear Cataract: A Lens Transport Problem. Ophthalmic. Res. 2000, 32, 185-194. [CrossRef]

42. Schoonooghe, S.; Kaigorodov, V.; Zawisza, M.; Dumolyn, C.; Haustraete, J.; Grooten, J.; Mertens, N. Efficient Production of Human Bivalent and Trivalent Anti-MUC1 Fab-ScFv Antibodies in Pichia Pastoris. BMC Biotechnol. 2009, 9, 70. [CrossRef]

43. Lee, M.E.; DeLoache, W.C.; Cervantes, B.; Dueber, J.E. A Highly Characterized Yeast Toolkit for Modular, Multipart Assembly. ACS Synth. Biol. 2015, 4, 975-986. [CrossRef] 
44. Lin-Cereghino, J.; Wong, W.W.; Xiong, S.; Giang, W.; Luong, L.T.; Vu, J.; Johnson, S.D. Condensed Protocol for Competent Cell Preparation and Transformation of the Methylotrophic Yeast Pichia Pastoris. BioTechniques 2005, 38, 44, 46, 48. [CrossRef] [PubMed]

45. Steenbeke, M.; De Bruyne, S.; Van Aken, E.; Glorieux, G.; Van Biesen, W.; Himpe, J.; De Meester, G.; Speeckaert, M.; Delanghe, J. UV Fluorescence-Based Determination of Urinary Advanced Glycation End Products in Patients with Chronic Kidney Disease. Diagnostics 2020, 10, 34. [CrossRef] [PubMed]

46. Kumar, A.; Singh, C.N.; Glybina, I.V.; Mahmoud, T.H.; Yu, F.-S.X. Toll-like Receptor 2 Ligand-Induced Protection against Bacterial Endophthalmitis. J. Infect. Dis. 2010, 201, 255-263. [CrossRef] [PubMed]

47. Zarina, S.; Zhao, H.R.; Abraham, E.C. Advanced Glycation End Products in Human Senile and Diabetic Cataractous Lenses. Mol. Cell Biochem. 2000, 210, 29-34. [CrossRef] [PubMed]

48. Roe, J.H. A colorimetric method for the determination of fructose in blood and urine. J. Biol. Chem. 1934, 107, 15-22. [CrossRef] 